Nature Geoscience

January 2009, volume 2 (1), Pages 67 - 72

http://dx.doi.org/10.1038/ngeo382

Copyright (c) 2009 Nature Publishing Group
Archimer http://www.ifremer.fr/docelec/ Archive Institutionnelle de l'Ifremer

The original publication is available at http://www.nature.com

\title{
Surprising return of deep convection to the subpolar North Atlantic Ocean in winter 2007-2008
}

\author{
Kjetil Våge ${ }^{1,{ }^{*}}$, Robert S. Pickart ${ }^{1}$, Virginie Thierry ${ }^{2}$, Gilles Reverdin ${ }^{3}$, Craig M. Lee ${ }^{4}$, Brian Petrie $^{5}$, Tom \\ A. Agnew ${ }^{6}$, Amy Wong ${ }^{6}$ \& Mads H. Ribergaard \\ ${ }^{1}$ Woods Hole Oceanographic Institution, Woods Hole, Massachusetts 02543, USA \\ 2 IFREMER, Laboratoire de Physique des Océans, UMR 6523 CNRS/IFREMER/IRD/UBO, 29280 Plouzané, \\ France \\ ${ }^{3}$ Laboratoire d'Océanographie Dynamique et de Climatologie, FR-75252 Paris, France \\ ${ }^{4}$ Applied Physics Laboratory, University of Washington, Seattle, Washington 98105, USA \\ ${ }^{5}$ Bedford Institute of Oceanography, Dartmouth, Nova Scotia B2Y 4A2, Canada \\ ${ }_{6}^{6}$ Meteorological Service of Canada, Downsview, Ontario M3H 5T4, Canada \\ ${ }^{7}$ Danish Meteorological Institute, DK-2100 Copenhagen, Denmark \\ *: Corresponding author : K. Vage, email address : kjetil@whoi.edu
}

\begin{abstract}
:
In the process of open-ocean convection in the subpolar North Atlantic Ocean, surface water sinks to depth as a distinct water mass, the characteristics of which affect the meridional overturning circulation and oceanic heat flux. In addition, carbon is sequestered from the atmosphere in the process. In recent years, this convection has been shallow or non-existent, which could be construed as a consequence of a warmer climate. Here we document the return of deep convection to the subpolar gyre in both the Labrador and Irminger seas in the winter of 2007-2008. We use profiling float data from the Argo programme to document deep mixing. Analysis of a variety of in situ, satellite and reanalysis data shows that contrary to expectations the transition to a convective state took place abruptly, without going through a phase of preconditioning. Changes in hemispheric air temperature, storm tracks, the flux of fresh water to the Labrador Sea and the distribution of pack ice all contributed to an enhanced flux of heat from the sea to the air, making the surface water sufficiently cold and dense to initiate deep convection. Given this complexity, we conclude that it will be difficult to predict when deep mixing may occur again.
\end{abstract}

The subpolar North Atlantic Ocean is a critical component of the global climate system. Deep convection in the Labrador and Irminger Seas produces the water mass known as Labrador Sea Water (LSW)1. This results in a net transfer of heat from the ocean to the atmosphere, which is balanced by northward advection of heat via the surface limb of the meridional overturning circulation (MOC). In response to global warming, most climate models predict a decline of the MOC, often due to a reduction of LSW formation (e.g. ref. 2). The ocean is also an important sink of atmospheric CO2, and, as a result of dense water formation and transformation, more 
anthropogenic carbon per unit area is stored in the subpolar North Atlantic than in any other ocean ${ }^{3}$. Furthermore, LSW is entrained by the dense waters overflowing the Greenland-Scotland Ridge ${ }^{4}$. The composite water mass product, known as North Atlantic Deep Water, is found throughout the World Ocean ${ }^{5}$ and forms the deep limb of the MOC. Through this pathway $\mathrm{CO}_{2}$ can be sequestered in the abyssal ocean for centuries, but the pathway is only active as long as the depth of winter convection exceeds $1000 \mathrm{~m}^{6}$.

Since the mid-1990s, convection in the Labrador Sea has been shallow - and at times nearly absent $^{6-8}$. The only major exception was the winter of 1999-00 (forming a water mass known as the "LSW 2000" class) $6 ; 9$. The last time convection occurred to depths of $2 \mathrm{~km}$ or more was during the late 1980s to early 1990s. This period was characterized by an extreme positive state of the North Atlantic Oscillation (NAO), which is the dominant pattern of climate variability in the North Atlantic ${ }^{10}$. A positive NAO index is associated with strong westerly winds, enhanced air-sea buoyancy fluxes, and is often linked to the onset of deep convection in the Labrador Sea ${ }^{11}$ and Irminger Sea ${ }^{12}$. However, there is not a one-to-one correspondence between convection and the NAO, since preconditioning plays an important role regulating the depth of convection ${ }^{6}$ and the NAO explains only some fraction of the atmospheric circulation variability ${ }^{13}$. A recent study ${ }^{14}$ has revealed a zonal shift of the Atlantic centers of action associated with changes in the NAO, making it more difficult to interpret the significance of the traditionally defined NAO index for oceanic convection. Here we show that convection returned unexpectedly to the subpolar gyre during the winter of 2007-08, with little evidence of preconditioning and in spite of the fact that the NAO index was lower than the previous winter. 


\section{Mixed layers in the subpolar North Atlantic}

Deep convection the North Atlantic subpolar gyre is commonly thought to occur principally in the Labrador Sea (e.g. ref. 6). This view is based primarily on shipboard hydrographic surveys, which are typically carried out in late spring and summer after the convection has ceased. Float data from the Argo programme provide a means to sample throughout the convective season, though at more limited spatial resolution. During winter 2007-08, most of the Argo floats drifting in the northwestern part of the subpolar gyre measured deep mixed layers. This provides further direct evidence that deep convection occurs outside the Labrador Sea ${ }^{15}$ (see also figure 13 of ref. 16).

Three floats, documented for several years, are highlighted in Figure 1. These floats sampled the Labrador Sea, Irminger Sea, and the region south of Greenland. The deepest mixed layers in the records, measured in winter 2007-08, were approximately $1800 \mathrm{~m}$ in the Labrador Sea, $1000 \mathrm{~m}$ in the Irminger Sea, and $1600 \mathrm{~m}$ south of Greenland (see the Methods section below for details on the determination of the mixed layer depth). All of these were isolated mixed layers, where the float encountered a patch of convected water that had begun to re-stratify in the upper-layer since its last contact with the atmosphere. We examined the stratification in the central Labrador and Irminger Seas using the Argo data to verify that the very low values of buoyancy frequency $(N)$ within the isolated mixed layers in Figure 1a could not have survived the previous summer. With the exception of a weakly stratified eddy encountered by float 4900500 in November 2006, the lowest values of $N$ were observed in the winter mixed layers. Hence, in light of the weak advective speeds in these regions ${ }^{17}$, the overturning that caused the mixed layers in Figure 1a 
occurred close to the point of observation. This is corroborated by recent shipboard observations in the Labrador Sea (showing convection to $1600 \mathrm{~m})^{18}$ and moored time series in the Irminger Sea (revealing mixed layers to nearly $1000 \mathrm{~m}$, Femke de Jong, personal communication). The deepest mixed layers reaching the surface that were observed by the profiling floats in winter 2007-08 were approximately $1600 \mathrm{~m}$ in the Labrador Sea (floats 4900494 and 4900677), $700 \mathrm{~m}$ in the Irminger Sea (float 6900240), and $1300 \mathrm{~m}$ south of Greenland (float 4900537). The properties of the LSW formed last winter are similar to the LSW 2000 class $^{6}$. Interestingly, an $800 \mathrm{~m}$ deep mixed layer was measured by float 6900240 during winter 2006-07 in the northeastern Irminger Sea (Fig. 1c), in a region where deep mixed layers have previously been reported ${ }^{19 ; 20}$.

To put the winter of 2007-08 into perspective, a climatology of mixed layer depths was created for the period 2000-07, hereafter referred to as the base period (the Labrador and Irminger Seas were not well sampled before winter 2003). In particular, for each winter (Feb-Apr), and for each given float, only mixed layers deeper than $80 \%$ of the maximum recorded mixed layer depth were included. This was done to isolate the mixed layers recorded near the time and location of the peak convective activity, thereby avoiding a shallow bias associated with the non-uniform temporal and spatial character of convection. All of the profiles satisfying this criterion (28\% of the total winter profiles) were combined into a single data set and interpolated onto a $1^{\circ} \times 1^{\circ}$ grid using a Laplacian-spline interpolator (Fig. 2, filled contours). The resulting spatial distribution of mixed layer depths for the base period indicates that the deepest mixing occurred in the western Labrador Sea, consistent with previous wintertime hydrographic surveys ${ }^{1 ; 21}$ and PALACE and SOLO float observations $^{22}$. A second region of enhanced convection is found south of Greenland. In general, 


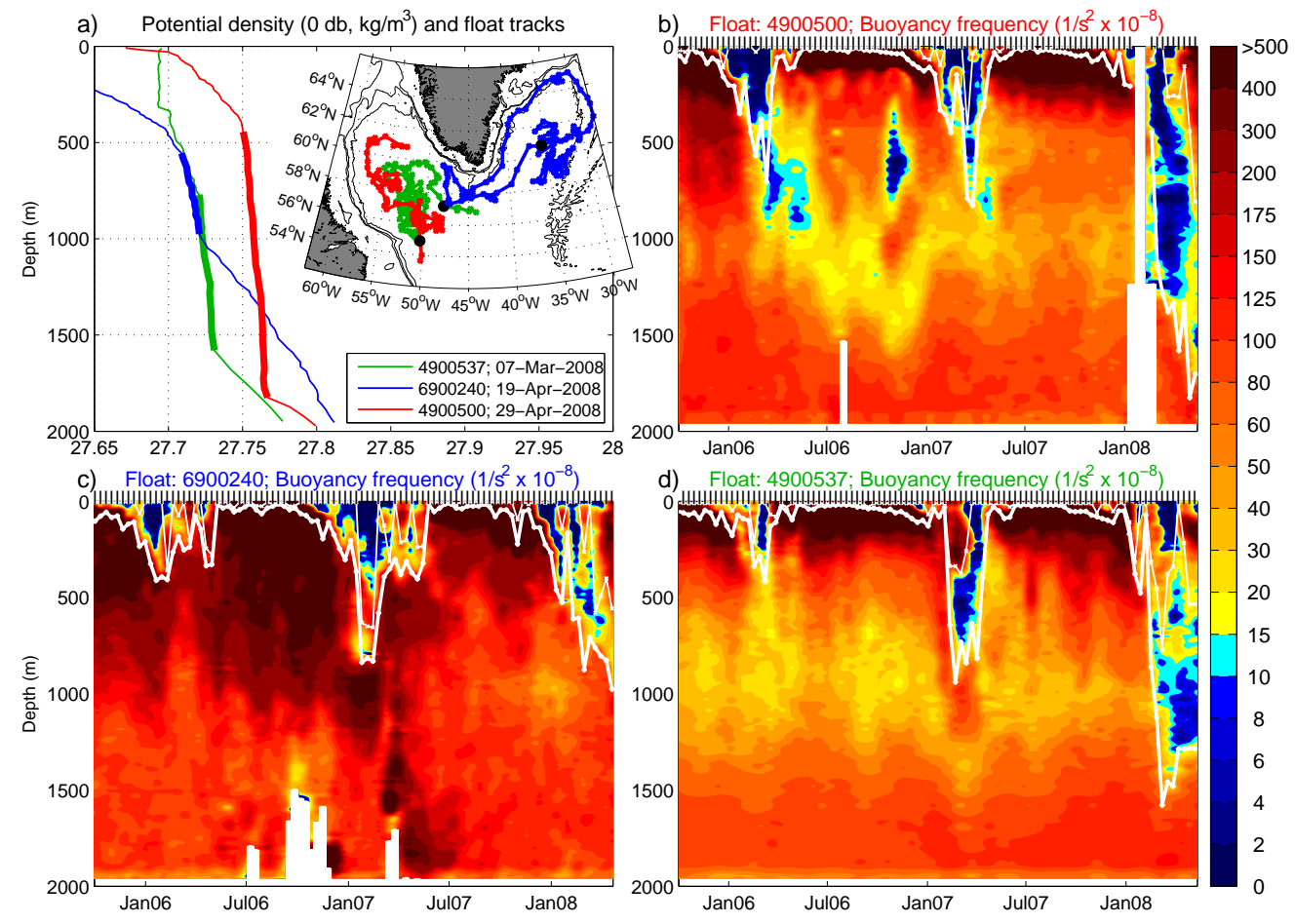

Figure 1: Potential density and buoyancy frequency squared for three selected Argo floats drifting in the Labrador and Irminger Seas from 2006-08. (a) Profiles showing the deepest recorded mixed layer in the Labrador Sea (red), in the Irminger Sea (blue), and south of Greenland (green). The inset shows the trajectories of each float and the locations of the highlighted profiles (black dots). (b-d) Temporal evolution of buoyancy frequency along the trajectories of floats 4900500 (b), 6900240 (c), and 4900537 (d). The white lines indicate the extent of the deepest mixed layer, and the vertical bars along the top denote the time of each profile along the trajectory. 
the overturning throughout the 8-year base period was shallow (less than $1000 \mathrm{~m}$ ). By contrast, the mixed layers observed during winter 2007-08 (Fig. 2, triangles) were significantly deeper (by more than $1000 \mathrm{~m}$ in some instances). One sees enhanced mixing in the western Labrador Sea, in the region south of Greenland, and in the southern Irminger Sea east of Cape Farewell. It is clear that deep convection returned to a broad area of the western North Atlantic subpolar gyre in 2007-08; the obvious question is, why.

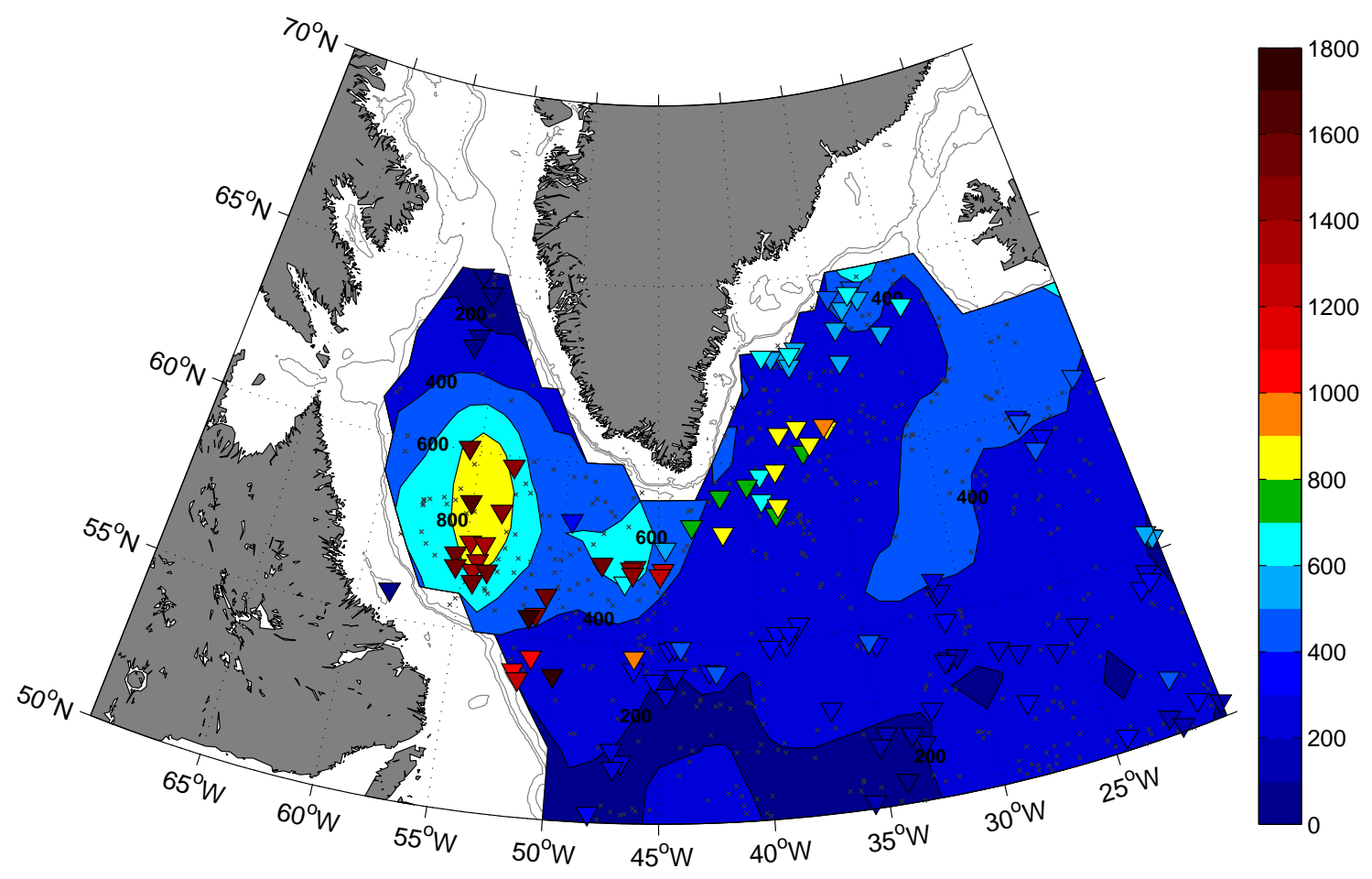

Figure 2: Changes in wintertime mixed layer depth distribution. The February - April mixed layer depths from winter 2007-08 (triangles) are contrasted to the average mixed layer depths for the period 2000-07 (filled contours). Only mixed layers deeper than $80 \%$ of the maximum mixed layer depth recorded by each float were included. The black crosses indicate the locations of the data points. The depth contours are 500,1000, and $2000 \mathrm{~m}$. 


\section{Atmospheric forcing}

Applying a bulk formula, as described in the Methods section, we computed winter-averaged (Dec-Feb) heat flux anomalies for each of the winters of this decade, relative to the base period (Fig. 3). It is immediately obvious that the winter of 2007-08 was much more severe than the previous winters in terms of heat removal from the ocean. In particular, a band of strong heat flux anomalies exceeding $100 \mathrm{~W} / \mathrm{m}^{2}$ extends from the ice edge in the Labrador Sea, around southern Greenland into the Irminger Sea. Diagnosis of the heat flux components reveals that the main cause of the enhanced heat flux was unusually cold air temperatures (and associated low humidities) during this past winter. Figure 4 shows the $2 \mathrm{~m}$ North American Regional Reanalysis (NARR) air temperature anomalies for the individual months of December 2007 through February 2008, relative to monthly climatologies of the base period. The temperature over the northwestern part of the subpolar gyre was several degrees colder than the corresponding temperature of the base period for each of the months. Consistent with this, the air temperature recorded at the Prins Christian Sund meteorological station near Cape Farewell was $2.8^{\circ} \mathrm{C}$ colder in winter 2007-08 than the corresponding mean of the base period.

As seen in Figure 4, there is a clear relationship between the air temperature anomalies in the Labrador Sea in winter 2007-08 and the location of the ice edge. Here we define the ice edge as the location of $50 \%$ ice concentration (the results are not sensitive to this definition). In 2007-08 the edge of the pack-ice extended significantly farther into the Labrador Basin compared to the base period (compare the grey and brown lines in Figure 4). The largest air temperature anomalies, 


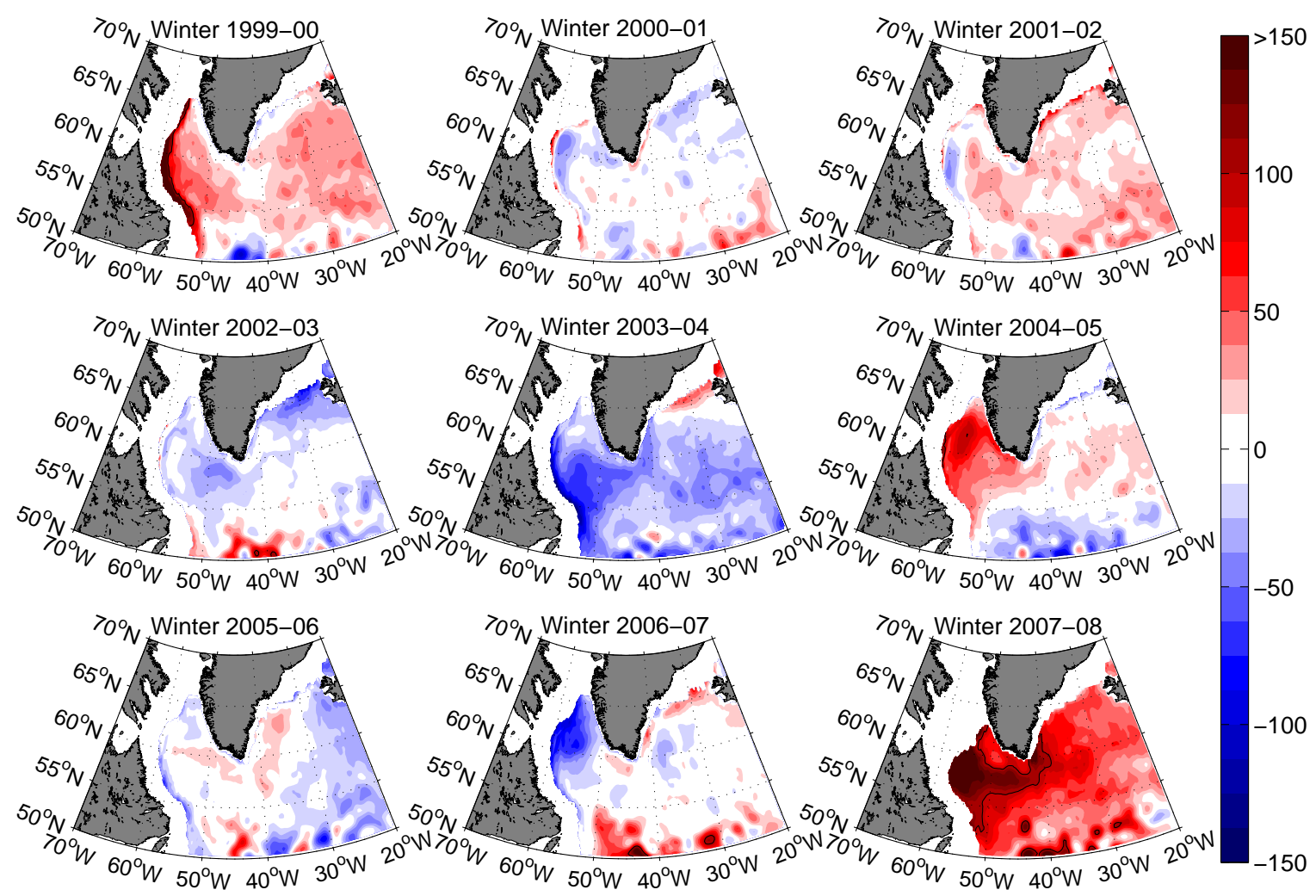

Figure 3: Interannual variability of wintertime air-sea heat flux. Each panel shows the mean December through February bulk heat flux anomaly field $\left(\mathrm{W} / \mathrm{m}^{2}\right)$ for the given winter relative to the $2000-07$ base period. The $100 \mathrm{~W} / \mathrm{m}^{2}$ isoline is contoured.

those exceeding $-6^{\circ} \mathrm{C}$, are found where the ice edge from winter 2007-08 extended past the ice edge from the base period. However, low air temperatures extended well beyond the ice edge across the basin into the southwest Irminger Sea. As seen below, this is because the anomalously large amounts of ice allowed the cold air emanating from the North American continent to remain largely unmodified by air-sea exchange as it passed eastward to the interior basin where convection occurred.

During most of the base period (the winters 2001-06) the NAO index was close to zero or 


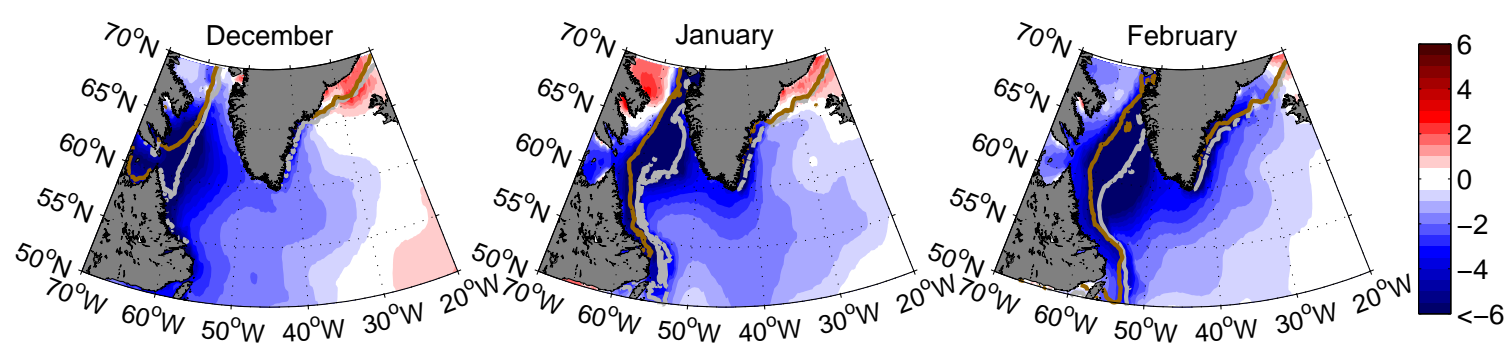

Figure 4: Relationship between air temperature and ice concentration in winter 2007-08. Monthly mean air temperature anomalies (colour) relative to the 2000-07 base period are shown, overlain by the 50\% ice concentration limits from 2007-08 (grey contours), and mean 50\% ice concentration limits for the base period (brown contours)

negative, which is consistent with the fact that deep convection did not take place in the subpolar gyre during this time. By contrast, during the last two winters (2006-07 and 2007-08) the NAO index was above +2 , and, as is typical for such states, there were westerly winds throughout much of the western subpolar gyre. However, deep convection occurred only during the latter winter (the mixed layer depths recorded during winter 2006-07 were similar to the climatological values in Figure 2). Consideration of the winter-averaged surface wind field anomalies, relative to the base period, suggests why. As seen in Figure 5a, the wind vector anomalies in 2006-07 were generally from the east throughout most of the Labrador Sea. Furthermore, the anomaly pattern in the vicinity of southern Greenland for that winter is consistent with an atmospheric flow regime known as the reverse Greenland tip jet ${ }^{23}$, which typically does not lead to deep mixing ${ }^{24}$.

In contrast, the surface wind field anomaly for winter 2007-08 shows very strong westerly winds off the Labrador ice edge (Fig. 5b), which, in light of Figure 4, boosted the advection of cold air toward the region of deep convection. In addition, the anomalously strong westerly 

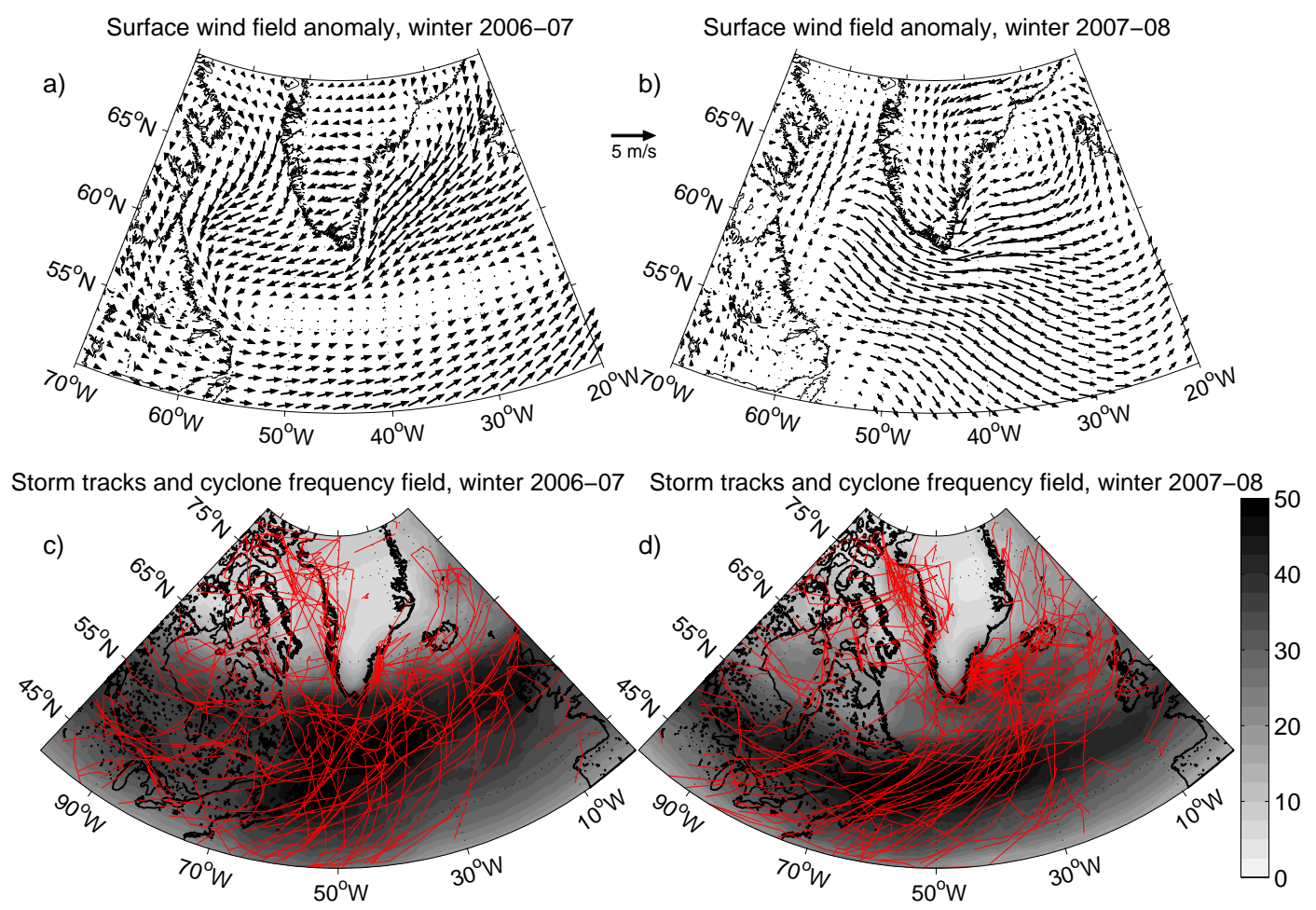

Figure 5: Wind anomalies and storm properties for the two high NAO winters of 2006-07 and 2007-08. Top row: NARR surface wind vector anomalies (m/s, every 21 st vector) relative to the 2000-07 base period. Bottom row: Storm tracks (red lines) and cyclone frequency field (grey shading).

winds south and east of Cape Farewell suggest that a larger number of forward Greenland tip jet events ${ }^{23}$ took place during this winter. Tip jets are intense, small-scale wind phenomena that occur near the southern tip of Greenland ${ }^{25}$ and arise due to interaction between cyclones and the high local orography ${ }^{23}$. The forward tip jet is known to force convection in the Irminger Sea $^{26 ; 27}$. Indeed, using an objective empirical orthogonal function (EOF) $\operatorname{method}^{26}$, we verified that more forward tip jets occurred during winter 2007-08 than in winter 2006-07. While the exact number of tip jets is sensitive to the chosen threshold wind speed, for the threshold used 
previously in the literature ${ }^{26}$ there were 17 and 27 events for the extended winters (Nov-Apr) of 2006-07 and 2007-08, respectively. This is part of the reason why deep mixed layers were observed not only in the western Labrador Sea this past winter, but also south of Greenland and east of Cape Farewell (Fig. 2).

\section{Storm patterns}

In order to examine the relationship between the convective activity taking place on both sides of Greenland, we performed a statistical analysis of various metrics for each of the winters during this decade (2000-08). It was found that a significant correlation $(-0.41$ to -0.64$)$ exists between the air temperature anomaly in the central Labrador Sea and the value of the forward tip jet EOF, with a time lag of 6-9 hours. This implies that tip jet events in the Irminger Sea often follow cold air outbreaks over the Labrador Sea. Inspection of the NARR fields reveals that the same storms that pull cold air off of eastern Canada into the Labrador Sea, tend to cause high winds in the lee of Cape Farewell as the low pressure systems progress eastward along the storm track. Therefore, conditions that favour deep convection in both basins often arise due to the same set of storms.

It still remains to be determined why there were such big differences in the wind field anomalies between the winters of 2006-07 and 2007-08, despite the fact that the NAO index was comparable for both years (stronger, in fact, for winter 2006-07). Analysis of the National Centers for Environmental Prediction (NCEP) sea level pressure data and calculated storm trajectories 
sheds light on this. Figure 5c,d (grey shading) show the cyclone frequency field for the two winters, where cyclone frequency denotes how often a given grid point in the domain is contained within a cyclone (as defined in the Methods section) relative to the full period. In terms of the number and strength of low pressure systems passing through the domain, the two winters were similar. However, the tracks of the storms during winter 2007-08 tended to be shifted more to the south (Fig. 5, red lines). In particular, the cyclones followed a more well-defined track from the east coast of North America toward the Irminger Sea. While it is well known that changes in the North Atlantic storm track associated with positive versus negative states of the NAO index can have an impact on convection in the Labrador Sea ${ }^{11}$, the results presented here indicate that even moderate shifts in the storm track - within a high NAO regime - can have profound consequences.

\section{Preconditioning}

It is generally believed that preconditioning of the water column is conducive for the onset of deep convection, whether it be strengthening of the cyclonic circulation or the presence of remnant convected water from previous winters. In this regard, the return of deep convection to the Labrador and Irminger Seas in winter 2007-08 was a surprise. As seen in Figure 3, the air-sea heat flux in both seas was anomalously weak during the preceding winter, and the Argo floats showed relatively shallow mixed layer depths that winter. Furthermore, examination of the summer (May-Oct) Argo density data gives no indication of an enhanced gyre circulation. In particular, gridded lateral 
fields of isopycnal depth indicate that the density surfaces which eventually outcropped during winter 2007-08 in the Labrador and Irminger Seas were anomalously deep relative to the base period. This is consistent with the elevated sea surface height field compared to the period of deep convection in the early 1990s (ref. 28, updated through winter 2007-08, Sirpa Häkkinen, personal communication).

As detailed above, the large amount of pack ice in the northwest Labrador Sea this past winter played a major role in the onset of convection. Animations of sea ice motion using high resolution data from the Advanced Microwave Scanning Radiometer (AMSR-E) suggest that both local formation and export from Baffin Bay ${ }^{29}$ contributed to the heavy Labrador Sea ice cover. Values of liquid freshwater flux from 2004 to 2007, calculated using hydrographic data from the Davis Strait/Arctic Gateways project, show a trend of enhanced net freshwater flux into the Labrador Sea, with values of $96,107,133$, and $13610^{3} \mathrm{~m}^{3} / \mathrm{s}$, respectively, relative to a salinity of 34.8 . (The trend is statistically significant at the $95 \%$ confidence level.) Consistent with this, gridded Argo salinities in the upper $20 \mathrm{~m}$ reveal that the northern Labrador Sea was anomalously fresh in summer 2007 relative to the base period. By inhibiting mixed layer deepening through the fall, therefore causing increased cooling of the near-surface water column, this surplus of freshwater undoubtedly contributed to the enhanced local ice formation during winter 2007-08. We note that the increased liquid and frozen freshwater flux into the Labrador Sea was likely tied to the large export of sea ice from the Arctic Ocean that contributed to the record minimum in sea ice extent observed in summer $2007^{30}$. Ironically, this disappearance of Arctic sea ice, which has been linked to global warming, may have helped trigger the return of deep wintertime convection to the North 
Atlantic.

A similar sudden onset of deep convection in the Labrador Sea occurred during the extraordinarily cold winter of $1971-72^{31}$, also associated with an increased flux of freshwater to the sea (the Great Salinity Anomaly ${ }^{32}$ ). However, the main source of freshwater at that time was the West Greenland Current, which is believed to be the dominant pathway of freshwater into the interior $\operatorname{basin}^{33}$. Hence the entire Labrador Sea (not just the northern part) was capped by low salinity water in 1971-72. By contrast, in summer 2007 the surface waters of the central basin were in fact salty compared to the base period. We note, however, that the 2007-08 AMSR-E animation indicated significant equatorward ice flux in the East Greenland Current all the way to Cape Farewell, which is likely the downstream response of the recent enhanced ice export through Fram Strait ${ }^{34}$. As this pathway from the Arctic Ocean to the Labrador Sea is longer, it could be expected that freshening of the interior Labrador basin will occur in the near future. This means that next winter there may be the competing effects of a broad surface salinity cap (inhibiting deep convection) versus a preconditioned water column due to last year's remnant LSW (which is conducive for deep overturning).

The myriad of factors involving the atmosphere-ocean-ice system that led to the return of deep convection in winter 2007-08 highlights the complexity of the convective system in the North Atlantic, making it difficult to predict when deep mixing is likely to occur. A final notable aspect from last year was that the anomalously cold air temperatures over the subpolar North Atlantic in winter were not a local phenomenon. According to the Goddard Institute for Space Studies 
temperature anomaly timeseries ${ }^{35}$, the global temperature dropped $0.45^{\circ} \mathrm{C}$ between the winters 2006-07 and 2007-08. This decrease was particularly strong across northern North America, where the mean winter temperature was more than $3^{\circ} \mathrm{C}$ colder this past winter (Fig. 6). It is possible that the strong La Niña during winter 2007-08 may have contributed to this, suggesting that global atmospheric modes need to be considered as well when diagnosing convection in the North Atlantic.

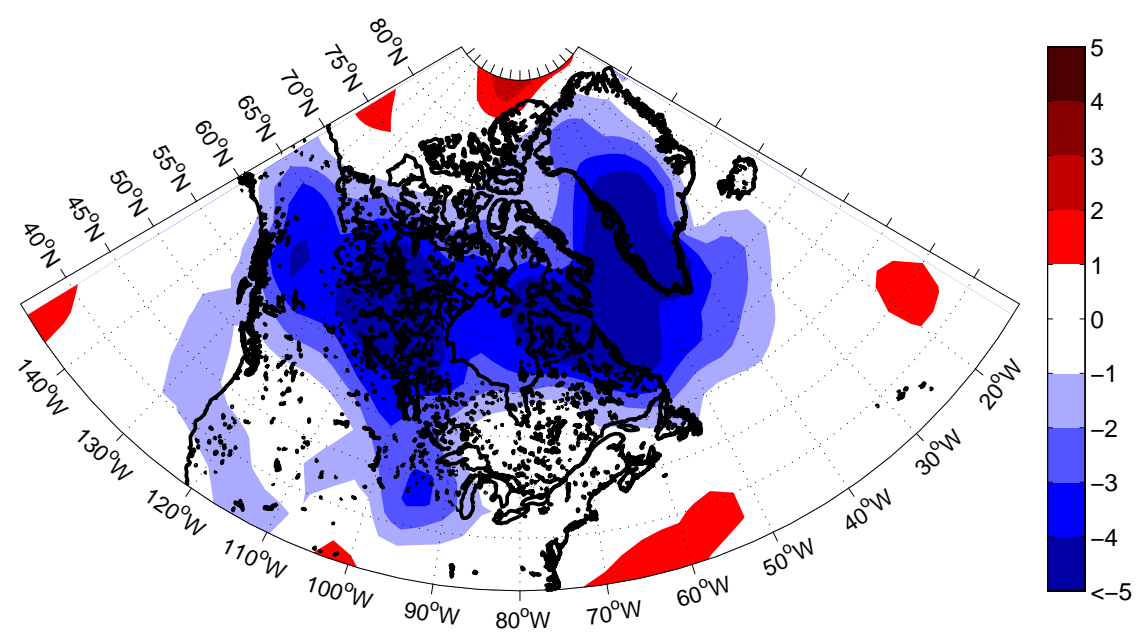

Figure 6: Hemispheric air temperature decrease in winter 2007-08. The difference in NCEP $2 \mathrm{~m}$ air temperature $\left({ }^{\circ} \mathrm{C}\right)$ over North America and Greenland between winters 2007-08 and 2006-07 is contoured.

\section{Methods}

The global program of profiling floats known as Argo has been in operation since 2000. The floats typically drift at a depth of $1000 \mathrm{~m}$, and, every 10 days, profile between a depth of $2000 \mathrm{~m}$ and 
the surface providing measurements of temperature and salinity. Rudimentary quality control is performed before the data become public. For this analysis we used a combination of real-time and delayed-mode data, the latter having been corrected for drift in the conductivity and pressure sensors $^{36}$. Only profiles assigned a quality flag of 1 or 2 (indicating "good" or "probably good" data) were used, and a subset of profiles known to have been mis-calibrated ${ }^{37}$ were excluded. Measurement uncertainties are expected to be less than $0.01^{\circ} \mathrm{C}$ and 0.03 for temperature and salinity, respectively. Late winter (Feb-Apr) mixed layer depths for the 2,023 profiles obtained between 2000-08 in the western subpolar gyre were estimated following a routine ${ }^{21}$ that involved manual inspection of each profile. An advantage of this procedure is that identification of mixed layers that have become isolated from the sea surface is possible. Both in the Labrador and Irminger Seas such isolated mixed layers are often observed during active convection ${ }^{21 ; 26}$, either in the form of stacked multiple mixed layers or as early stages of restratification. Through inspection of the temporal evolution of the regional mixed layers and trends in stratification, we are confident that the isolated mixed layers were formed by local convection during a given winter.

Air-sea turbulent heat fluxes were computed using a bulk algorithm ${ }^{38}$ with the inputs of wind speed, humidity, air temperature and sea surface temperature (SST). For the wind data we used the multiple-satellite blended Sea Winds product ${ }^{39}$, which has a space and time resolution of $0.25^{\circ}$ and 6 hours, respectively. SST and ice concentration were acquired from an optimum interpolated, blended analysis of satellite and in-situ data provided once per day at $0.25^{\circ}$ spatial resolution ${ }^{40}$. Humidity and air temperature were obtained from the high-resolution (32 km and 3 hours) NARR project $^{41}$. The bulk heat fluxes computed as such compare well with a newly released heat flux 
product $^{42}$ for the period of overlap (2000-06). Finally, storm tracks and cyclone field (defined as the area within the outermost closed $2 \mathrm{hPa}$ pressure contour of a low pressure system $)^{43}$ were computed, with global $\mathrm{NCEP}^{44}$ reanalysis sea level pressure data used as input.

\section{References}

[1] Clarke, R. \& Gascard, J. The formation of Labrador Sea Water. Part 1: Large-scale processes. Journal of Physical Oceanography 13, 1764-1778 (1983).

[2] Stouffer, R. et al. Investigating the causes of the response of the thermohaline circulation to past and future climate changes. Journal of Climate 19, 1365-1387 (2006).

[3] Sabine, C. et al. The oceanic sink for anthropogenic $\mathrm{CO}_{2}$. Science 305, 367-371 (2004).

[4] Dickson, R. \& Brown, J. The production of North Atlantic Deep Water: Sources, rates and pathways. Journal of Geophysical Research 99, 12319-12341 (1994).

[5] Johnson, G. Quantifying Antarctic Bottom Water and North Atlantic Deep Water volumes. Journal of Geophysical Research 113, C05027, doi:10.1029/2007JC004477 (2008).

[6] Yashayaev, I. Hydrographic changes in the Labrador Sea, 1960-2005. Progress in Oceanography 73, 242-276 (2007).

[7] Lazier, J., Hendry, R., Clarke, R., Yashayaev, I. \& Rhines, P. Convection and restratification in the Labrador Sea, 1990-2000. Deep Sea Research I 49, 1819-1835 (2002). 
[8] Avsic, T., Karstensen, J., Send, U. \& Fischer, J. Interannual variability of newly formed Labrador Sea Water from 1994 to 2005. Geophysical Research Letters 33, L21S02, doi:10.1029/2006GL026913 (2006).

[9] Yashayaev, I., van Aken, H., Holliday, N. \& Bersch, M. Transformation of the Labrador Sea Water in the subpolar North Atlantic. Geophysical Research Letters 34, L22605, doi:10.1029/2007GL031812 (2007).

[10] Hurrell, J. Decadal trends in the North Atlantic Oscillation: Regional temperatures and precipitation. Science 269, 676-679 (1995).

[11] Dickson, R., Lazier, J., Meincke, J., Rhines, P. \& Swift, J. Long-term coordinated changes in the convective activity of the North Atlantic. Progress in Oceanography 38, 241-295 (1996).

[12] Pickart, R., Straneo, F. \& Moore, G. Is Labrador Sea Water formed in the Irminger Basin? Deep Sea Research I 50, 23-52 (2003).

[13] Hurrell, J. et al. Atlantic climate variability and predictability: A CLIVAR perspective. Journal of Climate 19, 5100-5121 (2006).

[14] Cassou, C., Terray, L., Hurrell, J. \& Deser, C. North Atlantic winter climate regimes: Spatial asymmetry, stationarity with time, and oceanic forcing. Journal of Climate 17, 1055-1068 (2004).

[15] Falina, A., Sarafanov, A. \& Sokov, A. Variability and renewal of Labrador Sea Water 
in the Irminger Basin in 1991-2004. Journal of Geophysical Research 112, C01006, doi:10.1029/2005JC003348 (2007).

[16] Centurioni, L. \& Gould, W. Winter conditions in the Irminger Sea observed with profiling floats. Journal of Marine Science 62, 313-336 (2004).

[17] Lavender, K., Davis, R. \& Owens, W. Mid-depth recirculation observed in the interior Labrador and Irminger Seas by direct velocity measurements. Nature 407, 66-69 (2000).

[18] Yashayaev, I. \& Loder, J. Enhanced production of Labrador Sea Water in 2008. Geophysical Research Letters (accepted for publication).

[19] Ólafsson, J. Winter mixed layer nutrients in the Irminger and Iceland seas, 1990-2000. ICES Marine Science Symposia 219, 329-332 (2003).

[20] Reverdin, G., Verbrugge, N. \& Kushnir, Y. Upper ocean variability between Iceland and Newfoundland, 1993-1998. Journal of Geophysical Research 104, 29599-29611 (1999).

[21] Pickart, R., Torres, D. \& Clarke, R. Hydrography of the Labrador Sea during active convection. Journal of Physical Oceanography 32, 428-457 (2002).

[22] Lavender, K., Davis, R. \& Owens, W. Observations of open-ocean deep convection in the Labrador Sea from subsurface floats. Journal of Physical Oceanography 32, 511-526 (2002).

[23] Moore, G. \& Renfrew, I. Tip jets and barrier winds: A QuikSCAT climatology of high wind speed events around Greenland. Journal of Climate 18, 3713-3725 (2005). 
[24] Sproson, D., Renfrew, I. \& Heywood, K. Atmospheric conditions associated with oceanic convection in the south-east Labrador Sea. Geophysical Research Letters 35, L06601, doi:10.1029/2007GL032971 (2008).

[25] Doyle, J. \& Shapiro, M. Flow response to large-scale topography: The Greenland tip jet. Tellus 51, 728-748 (1999).

[26] Våge, K., Pickart, R., Moore, G. \& Ribergaard, M. Winter mixed-layer development in the central Irminger Sea: The effect of strong, intermittent wind events. Journal of Physical Oceanography 38, 541-565 (2008).

[27] Pickart, R., Spall, M., Ribergaard, M., Moore, G. \& Milliff, R. Deep convection in the Irminger Sea forced by the Greenland tip jet. Nature 424, 152-156 (2003).

[28] Häkkinen, S. \& Rhines, P. Decline of subpolar North Atlantic circulation during the 1990s. Science 304, 555-559 (2004).

[29] Kwok, R. Baffin Bay ice drift and export: 2002-2007. Geophysical Research Letters 34, L19501, doi:10.1029/2007GL031204 (2007).

[30] Zhang, J., Lindsay, R., Steele, M. \& Schweiger, A. What drove the dramatic retreat of Arctic sea ice during summer 2007? Geophysical Research Letters 35, L11505, doi:10.1029/2008GL034005 (2008).

[31] Lazier, J. Oceanographic conditions at Ocean Weather Ship BRAVO, 1964-1974. Atmosphere-Ocean 18, 227-238 (1980). 
[32] Dickson, R., Meincke, J., Malmberg, S.-A. \& Lee, A. The "Great Salinity Anomaly" in the northern North Atlantic 1968-1982. Progress in Oceanography 20, 103-151 (1988).

[33] Schmidt, S. \& Send, U. Origin and composition of seasonal Labrador Sea freshwater. Journal of Physical Oceanography 37, 1145-1454 (2007).

[34] Smedsrud, L., Sorteberg, A. \& Kloster, K. Recent and future changes of the Arctic sea-ice cover. Geophysical Research Letters (accepted for publication).

[35] Hansen, J., Ruedy, R., Glascoe, J. \& Sato, M. GISS analysis of surface temperature change. Journal of Geophysical Research 104, 30997-31022 (1999).

[36] Wong, A., Johnson, G. \& Owens, W. Delayed-mode calibration of autonomous CTD float profiling salinity data by $\theta$-S climatology. Journal of Atmospheric and Oceanic Technology 20, 308-318 (2003).

[37] Willis, J., Lyman, J., Johnson, G. \& Gilson, J. Correction to "Recent cooling of the upper ocean”. Geophysical Research Letters 34, L16601, doi:10.1029/2007GL030323 (2007).

[38] Fairall, C. et al. Bulk parameterization of air-sea fluxes: Updates and verification for the COARE algorithm. Journal of Climate 16, 571-591 (2003).

[39] Zhang, H.-M., Bates, J. \& Reynolds, R. Assessment of composite global sampling: Sea surface wind speed. Geophysical Research Letters 33, L17714, doi:10.1029/2006GL027086 (2006). 
[40] Reynolds, R. et al. Daily high-resolution-blended analyses for sea surface temperature. Journal of Climate 20, 5473-5496(2007).

[41] Mesinger, F. et al. North American regional reanalysis. Bulletin of the American Meteorological Society 87, 343-360 (2006).

[42] Yu, L. \& Weller, R. Objectively analyzed air-sea heat fluxes for the global ice-free oceans (1981-2005). Bulletin of the American Meteorological Society 88, 527539 (2007).

[43] Wernli, H. \& Schwierz, C. Surface cyclones in the ERA-40 dataset (1958-2001), part I: Novel identification method and global climatology. Journal of the Atmospheric Sciences 63, 2486-2507 (2006).

[44] Kalnay, E. et al. The NCEP/NCAR 40-year reanalysis project. Bulletin of the American Meteorological Society 77, 437-471 (1996).

\section{Correspondence}

Correspondence and requests for materials should be addressed to Kjetil Våge (kjetil@whoi.edu). 


\section{Acknowledgments}

The authors wish to thank Tom Haine, Jamie Morison, Lisan Yu, Sirpa Häkkinen, Artem Sarafanov, Ignatius Rigor, Ron Kwok, Todd Mitchell, Harry Stern, and Olivia Martius for valuable suggestions. We thank Heini Wernli for providing the cyclone tracking algorithm and Roger Goldsmith for developing a Matlab tool to compute and analyze the tracks. Jim Hurrell kindly provided the NAO index timeseries. Argo data were obtained from the GODAE (www.usgodae.org) and Coriolis (www.coriolis.eu.org) data centers. The Sea Winds, OI SST, and NARR and NCEP reanalysis data sets were obtained from the NOAA National Climatic Data Center (www.ncdc.noaa.gov). The AMSR-E data were obtained from the National Snow and Ice Data Center (www.nsidc.org). We thank Jinbo Wang and Hendra Adiwidjaja for assistance with the reanalysis data. Support for this work was provided by the Ocean Sciences Division of the National Science Foundation.

\section{Competing interests statement}

The authors declare that they have no competing financial interests. 